\title{
CATATAN KEBERADAAN COSTUS AFER KER GAWL. (COSTACEAE) DI PULAU JAWA
}

\author{
Arifin Surya Dwipa Irsyam ${ }^{1 *}$, Rina Ratnasih Irwanto $^{2}$ \& Muhammad Rifqi Hariri ${ }^{3}$ \\ ${ }^{1}$ Herbarium Bandungense (FIPIA), Sekolah Ilmu dan Teknologi Hayati (SITH), \\ Institut Teknologi Bandung, Gd. Labtek VB, Jl. Let. Jen. Purn. Dr (HC) Mashudi No. 1, Sumedang \\ ${ }^{2}$ Sekolah Ilmu dan Teknologi Hayati (SITH), Institut Teknologi Bandung, Gd. Labtek XI, Jl. Ganeca No. 10, \\ Bandung \\ ${ }^{3}$ Pusat Konservasi Tumbuhan-Kebun Raya Bogor, Lembaga Ilmu Pengetahuan Indonesia (LIPI), \\ Jl. Ir. H. Juanda No. 13 Bogor \\ *corresponding email: arifin@sith.itb.ac.id
}

Arifin Surya Dwipa Irsyam, Rina Ratnasih Irwanto \& Muhammad Rifqi Hariri. 2019. Note on the Existence of Costus afer Ker Gawl. (Costaceae) in Java. Floribunda 6(2): 64-71. - An introduced Costus originated from Africa namely Costus afer Ker Gawl., has naturalized in Maribaya (Lembang), Dago Atas (Bandung), and IPB Dramaga Campus (Bogor). The presence of naturalized population of C. afer in Java was never reported before. This species has not reported in Flora of Java either. The morphological characters of $C$. afer are close to and can be misidentified as C. lucanusianus J. Braun \& K. Schum. The information about population and morphological character of C. afer is reported.

Keywords: Costaceae, Costus afer, Java, naturalized.

Arifin Surya Dwipa Irsyam, Rina Ratnasih Irwanto \& Muhammad Rifqi Hariri. 2019. Catatan Keberadaan Costus afer Ker Gawl. (Costaceae) di Pulau Jawa. Floribunda 6(2): 64-71. - Suatu jenis Costus introduksi dari Afrika, yaitu Costus afer Ker Gawl., telah ditemukan tumbuh ternaturalisasi di Maribaya (Lembang), Dago Atas (Bandung), dan Kampus IPB Dramaga, Bogor. Keberadaan populasi liar C. afer di Pulau Jawa belum pernah dilaporkan sebelumnya. Jenis tersebut juga belum terdaftar dalam Flora of Java. Secara morfologi, C. afer sering salah teridentifikasi sebagai C. lucanusianus J. Braun \& K. Schum. Informasi mengenai populasi liar dan ciri morfologi $C$. afer dilaporkan dalam catatan ini.

Kata kunci: Costaceae, Costus afer, Jawa, ternaturalisasi.

Costus L. merupakan anggota terbesar dalam suku Costaceae karena terdiri dari banyak jenis yang tersebar mulai dari kawasan Afrika Tropik hingga Amerika Tropik dengan pusat keanekaragaman terdapat di kawasan Neotropik (Specht \& Stevenson 2006). Sebanyak 24 jenis Costus terdapat di Afrika, sementara itu kawasan Neotropik terdiri atas 50 jenis (Andre et al. 2016; Maas-van de Kamer et al. 2016). Suwandi (1995) mencatat bahwa di kawasan Malesia terdapat 11 jenis Costus, yaitu C. acanthocephalus K.Schum., C. clemensiae Ridl., C. igneus N.E. Brown, C. globosus Blume, C. lucanusianus J.Braun \& K.Schum., C. malortieanus Wendl, C. microcephalus K.Schum., C. oligophyllus K.Schum., C. paradoxus K.Schum., C. sopuensis Maas \& $\mathrm{H}$. Maas, dan C. speciosus (Koen.) J.E.Smith. Sebagian jenis Costus telah banyak dibudidayakan sebagai tanaman hias dan diintroduksi ke daerah sebaran baru. Beberapa contohnya antara lain Costus spicatus (Jacq.) Sw., C. stenophyllus Standl. \& L.O. Williams, dan C. woodsonii Maas (Fayaz
2011; Chen et al. 2015).

Informasi mengenai keanekaragaman jenis Costus di Pulau Jawa telah tersedia dalam buku Flora of Java jilid ketiga yang memuat sebanyak empat jenis, yaitu C. globosus, C. speciosus, C. malortieanus, dan C. igneus (Backer \& Bakhuizen van den Brink 1968). Saat ini C. globosus dan $C$. speciosus telah dimasukkan ke dalam marga Cheilocostus, sedangkan C. igneus dikelompokkan dalam marga Chamaecostus. Penelitian terdahulu menunjukkan bahwa masih terdapat jenis-jenis tumbuhan yang belum terdata pada Flora of Java (Djarwaningsih 2010; Irsyam \& Chikmawati 2018; Hariri \& Irsyam 2018), sehingga sangat memungkinkan apabila masih terdapat jenis lain yang belum sempat dicatat oleh CA Backer \& RC Bakhuizen van den Brink jr. Pada tahun 1995, Suwandi mencatat adanya satu jenis tambahan di Jawa, yakni C. lucanusianus. Jenis tersebut ditanam di Kebun Raya Bogor (Suwandi 1995).

Berdasarkan pengamatan lapangan pada beberapa lokasi di Jawa Barat, telah ditemukan 
adanya populasi jenis Costus introduksi dari Afrika yang ternaturalisasi, yaitu C. afer Ker Gawl. Karakter morfologi jenis ini sangat mirip dengan $C$. lucanusianus J. Braun \& K. Schum. Informasi keberadaan populasi yang ternaturalisasi dan ciri pembeda antara $C$. afer dengan $C$. lucanusianus dilaporkan dalam tulisan berikut ini.

\section{BAHAN DAN METODE PENELITIAN}

Bahan yang diamati dalam penelitian ini yaitu sampel hasil koleksi dari lapangan, spesimen koleksi Herbarium Bogoriense (BO), dan koleksi hidup yang ditanam di Kebun Raya Bogor. Pengamatan lapangan dilakukan di Bogor (Kampus IPB Dramaga), Bandung (Kampus ITB Bandung, Dago Atas, dan Taman Hutan Raya Ir. H. Djuanda), Lembang (Maribaya), Purwakarta (Gunung Hejo, KM 96-Tol Cipularang), dan Sukabumi (Kawasan Kampung Adat Ciptagelar) pada Bulan Juli 2018. Pengambilan sampel dari lapangan mengikuti Rugayah et al. (2004). Bagian tumbuhan yang diambil adalah ranting berbunga atau berbuah. Data yang dicatat berupa titik koordinat, lokasi pengambilan sampel, ciri-ciri morfologi yang mungkin hilang saat pembuatan herbarium (indumentum, aroma rimpang, dan warna dari taruk, daun, bunga, serta buah), nama lokal, dan pemanfaatan. Sampel yang telah diambil selanjutnya dibawa ke Herbarium Bandungense (FIPIA), Sekolah Ilmu dan Teknologi Hayati, ITB, untuk diproses dan diamati lebih lanjut.

Sampel diidentifikasi menggunakan Flora of Tropical Africa (Baker 1898), A new phylogenybased generic classification of Costaceae (Zingiberales) (Specht \& Stevenson 2006), dan Monograph of African Costaceae (Maas-van de Kamer et al. 2016). Sementara terminologi yang dipakai dalam penulisan deskripsi mengacu pada Rifai \& Puryadi (2008).

\section{HASIL}

Costus afer Ker Gawl., Bot. Reg. 8: tab. 683. 1823; Hooker, Curtis’s Bot. Mag. 83: t. 4979. 1857; Baker, fl. Trop. Africa 7: 299. 1898; Schumann, Pflanzenr. 20: 392, 393. 1904; Koechlin, Fl. Gabon 9: 84, 85, 86. 1961; Koechlin, Fl. Cameroun 4: 92, 93. 1965; Hepper, Fl. West Trop. Africa, ed. 2:78. 1968; Lock, Kew Bull. 39: 842, 843. 1984; Maas-van de Kamer, Maas, Wieringa \& Specht, Blumea 61: 290, 291, 292, 293. 2016. Tipe: Ker-Gawler, Bot. Reg, 8: t. 683 (1823) (holo CGE!).
Costus sarmentosus Bojer, Ann. Sci. Nat., Bot., sér. 24: 262, t. 8. 1835. Tipe: Zanzibar, Bojer (1835) plate 8.

Costus trachyphyllus K.Schum., Bot. Jahrb. Syst.15(4): 420-421. 1892. Tipe: G.A. Schweinfurth-ser. 3, 206. (lecto K).

Costus edulis De Wild. \& T. Durand, Bull. Soc. Roy. Bot. Belgique38: 141. 1899. Tipe: Congo Kinshasa, Nyangwe, Mossungulore, anno 1896, Dewèvre 916a (holo BR).

Costus oblitterans K.Schum., Pflanzenr. IV, 46: 393. 1904. Tipe: Ghana ('Goldcoast'), Unknown collector s.n. (syn B hancur); Nigeria, Lagos, Millen s.n. (syn B hancur).

Costus deistelii K.Schum., Pflanzenr.IV, 46: 393. 1904. Tipe: Cameroon, South-West Province, Buea, Feb. 1900, Deistel 498 (holo B hancur).

Costus subbiflorus K.Schum., Pflanzenr. IV, 46: 394. 1904. Tipe: Tanzania, Lushoto Distr., 'Usambara, von Derema bis Magila ('Msassaberg'), häufig im Urwald z. B. bei Punga Ninga', 900 m, 21 Jan. 1893, Volkens 50 (lecto BM).

Costus pterometra K.Schum., Pflanzenr. IV, 46: 394. 1904. Tipe: South Sudan, 'Ghasaquellengebiet, Land der Niamniam am Nabambisso', 20 Feb. 1870, Schweinfurth III-204 (lecto K).

Costus anomocalyx K.Schum., Pflanzenr. IV, 46: 394. 1904. Tipe: Togo, 'Misahöhe, 496 m ü. M.', 15 Mar. 1894, Baumann 8 (holo B hancur).

Costus megalobractea K.Schum., Pflanzenr. IV, 46: 407. 1904. Tipe: Cameroon, South Province, Gross-Batanga, Braun s.n., anno 1888 (holo B hancur).

Costus bingervillensis A.Chev., Explor. Bot. Afrique Occ. Franç. 1: 627. 1920. Tipe: Ivory Coast, Bingerville region, Abidjan, Dabou, 19 Mar. 1905, Chevalier 15214 (lecto P).

Costus insularis A.Chev., Explor. Bot. Afrique Occ. Franç. 1: 627. 1920. Tipe: Guinea, Iles de Los, 25 Feb. 1905, Chevalier 13058 (holo P).

Terna, tegak, tinggi hingga $4 \mathrm{~m}$. Akar menyerabut. Rimpang jambon hingga kehijauan, tidak beraroma. Taruk berdaun tidak bercabang, spiral, hijau atau merah, gundul; ruas 1-9 cm. Daun tunggal, berseling; diameter pelepah daun 0.5-1 $\mathrm{cm}$; lidah daun melontar, merompang atau bercuping dua, ujung kemerahan, 4-10 mm, pangkal tidak berambut; tangkai daun 5-25 mm, hijau, gundul; helaian menjorong-melanset hingga membundar telur sungsang, $13-29.5 \times 3.5-10 \mathrm{~cm}$, pangkal menjantung dangkal hingga membaji, tepi rata hingga bergelombang, ujung melancip, permukaan adaksial gundul, hijau, permukaan abaksial 
gundul, pucat. Perbungaan bulir, membulat hingga melonjong, 4-7.5 × 3-5 cm, terminal; daun gagang tersusun spiral, membundar telur sungsang melebar hingga membundar telur-menyegitiga, $2-3 \times 1.4$ $3.5 \mathrm{~cm}$, hijau hingga berbercak merah, tepi merah, gundul; daun gantilan memerahu, 2-2.3 × 1-1.5 $\mathrm{cm}$, kehijauan, berbercak merah, ujung kemerahan; bunga 1-2 per daun gagang, banci, zigomorfik; daun kelopak berlekatan, $1 \times 1.5 \mathrm{~cm}$, bercuping 3; cuping daun kelopak tegak, menyegitiga, hijau, ujung kemerahan, mencuat; daun mahkota berlekatan, 3, menjorong, 3-4 × 1.2-1.5 cm, putih, gundul; bibir bunga 1 , mencorong hingga membundar telur sungsang, putih dengan tepian jambon pucat-jambon pekat atau putih seluruhnya, bergaris kuning menyolok di bagian tengah, 4.5-5 × 3.5$4.5 \mathrm{~cm}$, tepi berpicisan; petaloid menjorong, 3.3$4.5 \times 1.2-1.3 \mathrm{~cm}$, ujung jambon; kepala sari kuning, 7-8mm; putik 1; bakal buah tenggelam, 5$10 \mathrm{~mm}$, beruang 3, kehijauan; tangkai putik 3.7$3.8 \mathrm{~cm}$, membenang, putih; kepala putik mengginjal, 2-3 mm, kuning kehijauan. Buah dan biji tidak diamati.

Sebaran: C. afer berasal dari Afrika sebelah Timur Laut hingga Afrika Tropik sebelah Selatan. Saat ini, jenis tersebut telah diintroduksi ke berbagai kawasan tropis lainnya sebagai tanaman hias.

Habitat: Pada daerah sebaran aslinya, C. afer tumbuh di tempat terbuka, tepi jalan, pinggiran hutan, sekitar sumber air, dengan ketinggian 0-1770 $\mathrm{m}$ dpl (Maas-van de Kamer et al. 2016). Pada lokasi pengamatan, jenis ini tumbuh ternaturalisasi di tepi jalan, lahan terbengkalai, daerah yang ternaungi maupun terbuka, pinggiran tebing, dan sekitar daerah aliran sungai dengan ketinggian 250-1241 m dpl.

Nama lokal: Pacing (Sunda).

Spesimen yang diamati: Hortus Bogoriensis, No. XI.B.V.121, 3/11/1953, AHG Alston 12380 (BO); Hortus Bogoriensis, sub no. XV. K.B. LXVI.12, 24/2/1956, L.L. Forman 46 (BO); Kebun Raya Bogor, 03/12/1959, Martati 61 (BO); Arboretum belakang Masjid Al-Hurriyyah, Kampus IPB Dramaga, Bogor, 06/07/2018, Z. Al Anshori 180001 (FIPIA); tepi jalan dekat Desa Langensari, Maribaya, Lembang, 07/07/2018, ASD Irsyam 102 (FIPIA); Samping Masjid Al-Ikhlas, Komp. PPR ITB, Mekarwangi, Dago Atas, 09/07/2018, ASD Irsyam 106 (FIPIA); tepi sungai dekat Komp. PPR ITB, Mekarwangi, Dago Atas, 09/07/2018, ASD Irsyam 107 (FIPIA); Jl. Dalem Wangi, Mekarwangi, Dago Atas, 09/07/2018, ASD Irsyam 108 (FIPIA); Kampung Adat Ciptagelar, Kab. Sukabumi, 23/07/2018, ASD Irsyam 118 (FIPIA).
Etimologi: Epitet afer (afri, afares) berasal dari Bahasa Latin yang berarti 'berasal dari Afrika', dengan kata yang merujuk pada daerah sebaran asalnya (Gledhill 2008).

Pemanfaatan: C. afer banyak ditanam sebagai tanaman hias dan tumbuhan obat. Masyarakat Kampung Adat Ciptagelar menggunakan taruk $C$. afer untuk mengobati gigitan ular. Selain itu, taruknya juga dijadikan salah satu komponen dalam pembuatan minyak urut tradisional, dengan cara menghancurkan bagian taruk, lalu dicampur dengan jahe serta minyak kelapa. Sementara bagian daun digunakan sebagai salah satu syarat pelengkap untuk ritual nyawen yang dilakukan di leuit (bahasa Sunda) atau lumbung padi.

\section{PEMBAHASAN}

Costus afer Ker Gawl. merupakan tumbuhan terna yang tersebar luas mulai dari Afrika sebelah Timur Laut (Ethiopia, Sudan Selatan) hingga ke Afrika Tropik sebelah Selatan (Angola, Malawi, Mozambique, Zambia, dan Zimbabwe). Jenis ini pertama kali dideskripsikan pada tahun 1823 oleh Ker Gawler berdasarkan koleksi hidup yang ditanam di The Horticultural Society of London (saat ini bernama The Royal Horticultural Society). Koleksi tersebut dibawa oleh George Don dari Îles de Los, Sierra Leone, Afrika Barat (Ker Gawler 1823; Hooker 1857; Lock 1984; Crouch et al. 2007; Maas-van de Kamer et al. 2016). Secara morfologi, C. afer memiliki taruk berdaun berbentuk spiral dan warna bibir bunga yang menarik, sehingga jenis ini diintroduksi sebagai tanaman hias ke kawasan lainnya, seperti Singapura dan Australia (Anderson 1912; Randall 2007). Ciri morfologi C. afer ditunjukkan pada gambar 1 dan 2.

Kedatangan jenis ini di Indonesia tidak diketahui dengan pasti. Namun, jenis ini diduga pertama kali masuk melalui jalur budi daya. Berdasarkan data spesimen yang disimpan di Herbarium Bogoriense (BO), dua spesimen C. afer di Pulau Jawa, yaitu L.L. Forman 46 dan A.H.G. Alston 12380, berasal dari koleksi Kebun Raya Bogor. Spesimen Forman dikoleksi dari vak No. XV.K.B.LXVI.12 pada tanggal 24 Februari 1956, sementara spesimen Alston dikoleksi pada tanggal 24 Februari 1956 dari vak No. XI.B.V.121. C. afer telah direkam sebagai koleksi Kebun Raya Bogor dalam katalog tahun 1930. Koleksi C. afer yang ditanam berasal dari Papua, Kalimantan, Jawa, Maluku, Papua New Guinea, dan Afrika Tropis. Akan tetapi, koleksi dari Papua dan Kalimantan 
ternyata sudah ditanam sejak tahun 1904, sedangkan koleksi dari Maluku ditanam pada tahun 1914. Walaupun C. afer telah ditanam di Kebun Raya Bogor sejak awal abad keduapuluh, namun jenis tersebut belum tercatat dalam Flora of Java jilid ketiga (Backer \& Bakhuizen van den Brink 1968).

Sejauh ini, keberadaan C. afer di Pulau Jawa hanya direkam dari jalur budi daya saja. Namun, populasi C. afer ternaturalisasi telah ditemukan di
Kampus IPB Dramaga, Maribaya, Dago Atas, dan Kebun Raya Bogor. Keberadaan populasi C. afer di Pulau Jawa merupakan sebuah catatan baru, karena belum pernah dilaporkan sebelumnya. Di Kampus ITB Bandung (Labtek II dan IV) dan Kampung Adat Ciptagelar hanya ditemukan rumpun C. afer yang sengaja ditanam. Sementara di Taman Hutan Raya Djuanda dan Gunung Hejo tidak ditemukan C. afer budi daya maupun yang ternaturalisasi.
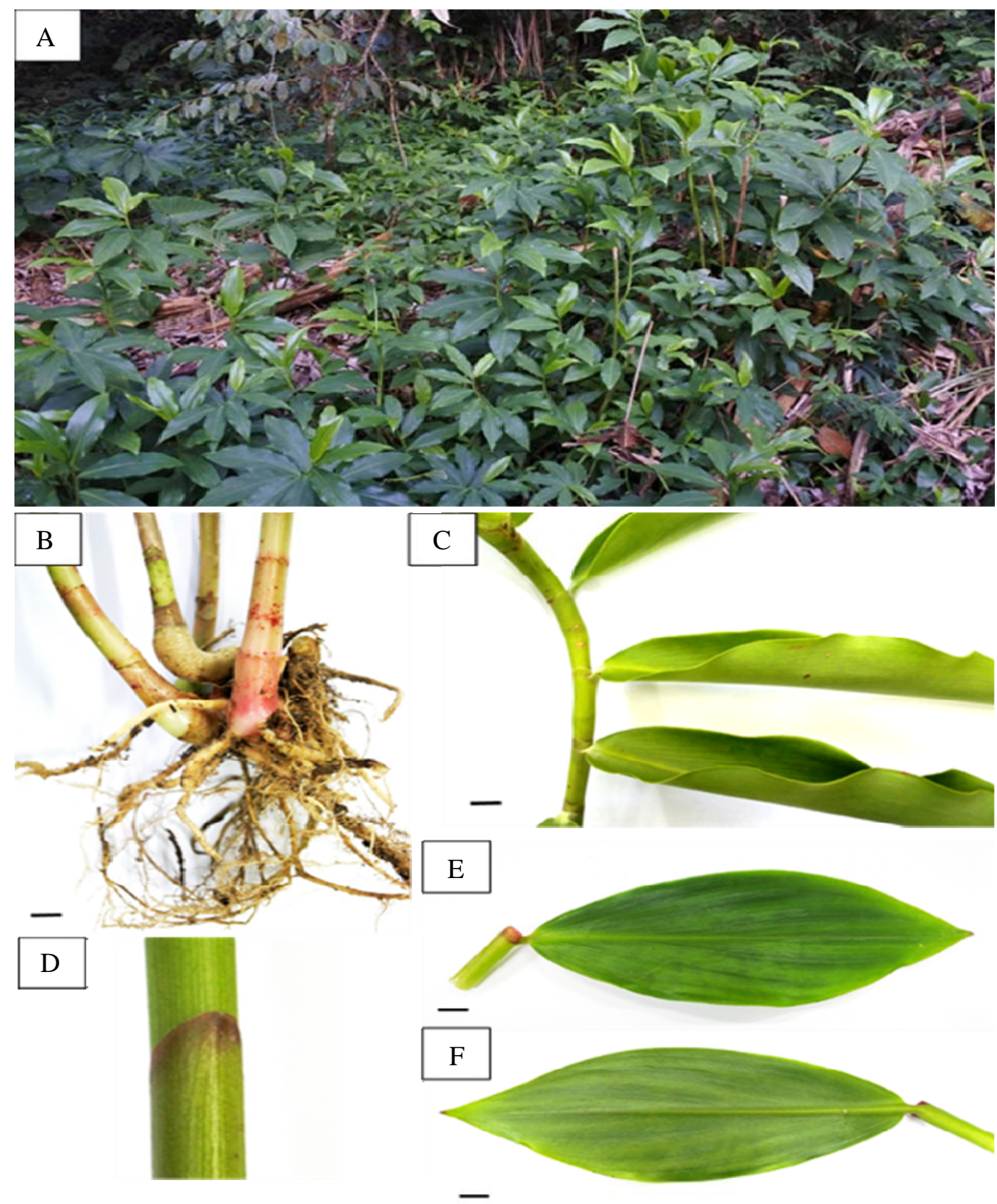

Gambar 1. Bagian organ vegetatif C. afer Ker Gawl. A. Perawakan; B. Rimpang; C. Taruk berbentuk spiral dengan daun yang tersusun berseling; D. Lidah daun dengan ujung berwarna kemerahan; E. Permukaan adaksial daun; F. Permukaan abaksial daun. Skala bar $=1 \mathrm{~cm}$. 

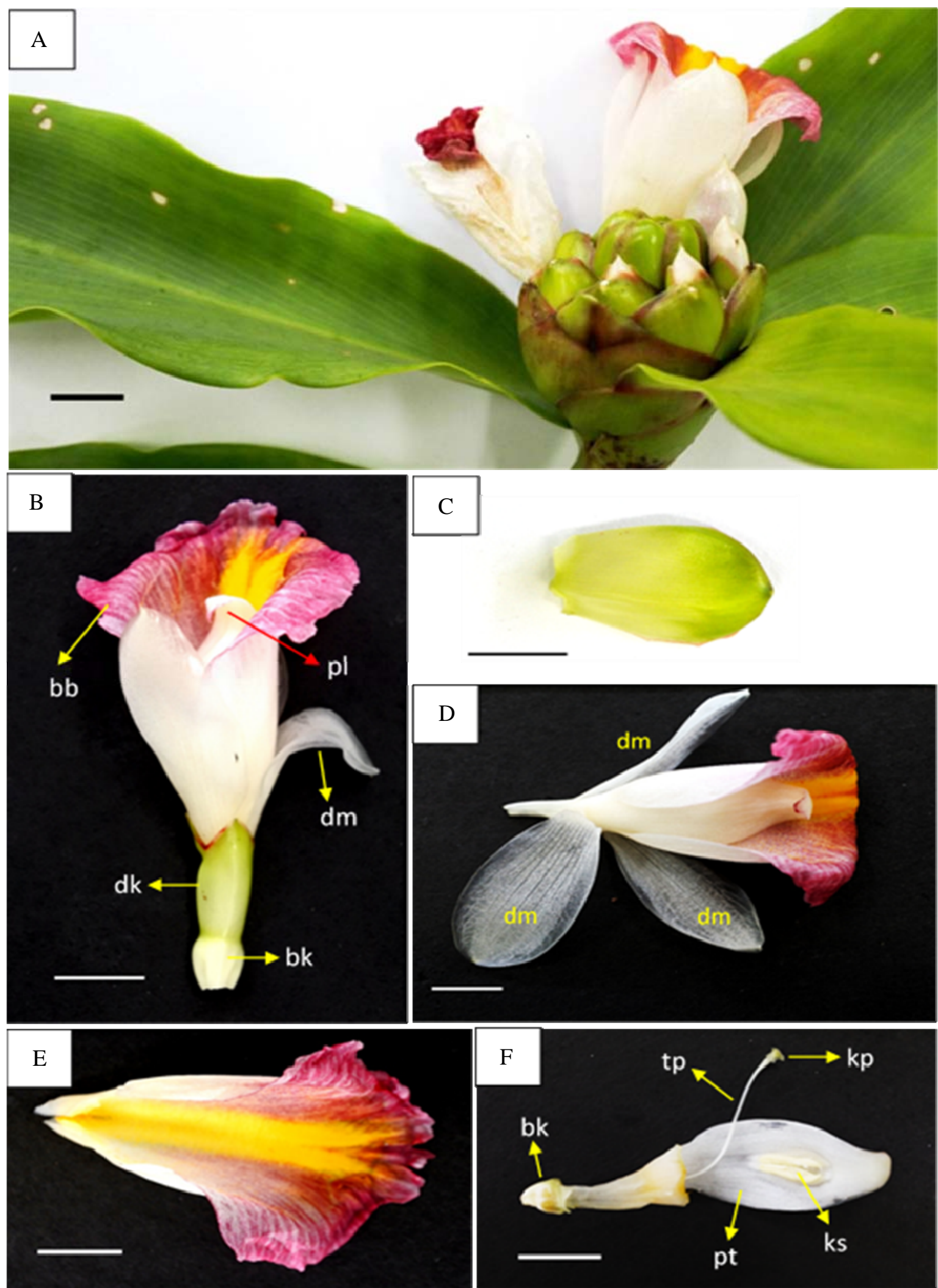

Gambar 2. Bagian organ generatif C. afer Ker Gawl. A. Satu karangan bunga; B. Satu helai bunga (bk = bakal buah, $\mathrm{dk}=$ daun kelopak; $\mathrm{dm}=$ daun mahkota, $\mathrm{pl}=$ petaloid, $\mathrm{bb}=$ bibir bunga); C. Daun gagang; D. Penampang daun mahkota (dm); E. Penampang bibir bunga; F. Alat reproduksi bunga (bk = bakal buah, $\mathrm{tp}=$ tangkai putik, $\mathrm{kp}=$ kepala putik, $\mathrm{pt}=$ petaloid, $\mathrm{ks}=$ kepala sari. Skala bar = $1 \mathrm{~cm}$. 
Sebagian besar populasi C. afer yang ternaturalisasi diamati berada di sekitar populasi yang sengaja ditanam. Oleh karena itu, populasi meliarnya berasal dari rumpun yang telah ditanam sebelumnya oleh masyarakat. Jenis ini telah lolos dari kultivasi dan ternaturalisasi, karena mampu bereproduksi secara konsisten dan mempertahankan populasinya tanpa adanya campur tangan manusia (Heenan et al. 1998; Richardson et al. 2000). Pada umumnya tumbuhan introduksi yang ternaturalisasi akan ditemukan dekat dengan lingkungan di mana manusia tinggal (Sullivan et al. 2004).

Satu populasi meliar C. afer yang ditemukan terdiri dari banyak rumpun anakan baru. Penyebarannya di lokasi pengamatan diduga melalui perkembangbiakan vegetatif, karena semua spesimen yang ditemukan tidak menghasilkan buah maupun biji. C. afer yang ditanam di The Horticultural Society of London juga tidak dapat menghasilkan biji, sehingga perbanyakan dilakukan secara vegetatif (Hooker 1857). Jenis ini dapat melakukan perkembangbiakan secara vegetatif dengan menghasilkan siungan (bulbil) yang tumbuh dari ruas taruk dan melalui mekanisme pemisahan rimpang (Maas-van de Kamer et al. 2016). Perkembangbiakan vegetatif secara vivipari juga ditemukan terjadi pada C. afer koleksi Kebun Raya Bogor meskipun Edeoga \& Okoli (1996) menyebutkan bahwa sifat tersebut hanya dapat ditemukan pada C. lucanusianus dan Costus hibrida.

Pengamatan morfologi menunjukkan bahwa C. afer memiliki ciri morfologi bunga yang bervariasi. Koleksi hidup di Kebun Raya Bogor (KRB) vak. XI.B.V.65 memiliki bibir bunga yang berwarna putih, bergaris kuning di bagian tengah, dan tanpa tepian jambon. Ciri tersebut sama seperti ciri yang disebutkan dalam protolog pada tahun 1823. Selain itu, koleksi pada vak. XI.B.II.33 memiliki perbungaan yang muncul dari ujung taruk tak berdaun, sehingga terlihat seperti perbungaan pada marga Zingiber Mill. (Zingiberaceae). Se- mentara semua sampel dari populasi meliar memiliki perbungaan yang muncul dari ujung taruk berdaun serta bibir bunga dengan tepian berwarna jambon dan garis kuning di bagian tengah. Variasi ciri morfologi yang diamati sesuai dengan deskripsi yang ditulis oleh Maas-van de Kamer et al. (2016).

Karakter morfologi $C$. afer sangat mirip dengan $C$. lucanusianus, sehingga sering mengalami salah identifikasi. Suwandi (1995) mengidentifikasi spesimen Martati 61 yang berasal dari KRB sebagai C. lucanusianus, karena ciri 2 bunga yang tumbuh pada setiap helai daun gagangnya. Akan tetapi, ciri tersebut juga dimiliki oleh C. afer (Maas-van de Kamer et al. 2016). Pengamatan morfologi terhadap 6 nomor koleksi C. afer (vak. XI.B.V.121，XI.B.V.125，XI.B.V.7，XI.B.V.111, XI.B.V.110, dan XI.B.V.65) dan 2 nomor koleksi C. lucanusianus (vak. XI.B.II.33 dan XI.B.II.46) yang ditanam di Kebun Raya Bogor menunjukkan bahwa semua koleksi tersebut merupakan C. afer. Spesimen Martati 61, juga menunjukkan ciri-ciri morfologi yang dimiliki oleh C. afer.

Pada tahun 1979, Maas menyebutkan bahwa C. lucanusianus memiliki bibir bunga yang berwarna putih dengan garis-garis ungu gelap (Maas 1979). Kemudian Maas-van de Kamer et al. (2016) mempertegas kembali perbedaan warna bibir bunga antara C. afer dengan C. lucanusianus. Bibir bunga $C$. afer berwarna putih polos atau dengan campuran jambon pucat hingga pekat. Sementara itu, C. lucanusianus memiliki bibir bunga berwarna putih dengan warna merah tua di bagian tepi. Selain warna bibir bunga, kedua jenis tersebut juga dapat dibedakan berdasarkan ciri keberadaan rambut pada pangkal lidah daun, bentuk helaian dan pangkal daun, warna dan tipe indumen pada permukaan abaksial daun, bentuk perbungaan, serta arah tumbuh cuping daun kelopak (Maas-van de Kamer et al. 2016). Perbandingan morfologi keduanya disajikan dalam Tabel 1.

Tabel 1. Perbandingan ciri morfologi C. afer dan C. lucanusianus

\begin{tabular}{lll}
\hline \multicolumn{1}{c}{ Ciri } & \multicolumn{1}{c}{ C. afer } & \multicolumn{1}{c}{$\begin{array}{c}\text { C. lucanusianus } \\
\text { (Maas-van de Kamer et al. 2016). }\end{array}$} \\
\hline Pangkal lidah daun & gundul & berambut panjang seperti jarum \\
Helaian daun & $\begin{array}{l}\text { menjorong-melanset hingga } \\
\text { membundar telur sungsang } \\
\text { menjantung dangkal hingga } \\
\text { Pangkal daun }\end{array}$ & menjorong \\
Warna abaksial daun & menjantung hingga menumpul \\
hijau pucat & keperakan \\
\hline
\end{tabular}


Tabel 1. Perbandingan ciri morfologi C. afer dan C. lucanusianus (lanjutan)

\begin{tabular}{|c|c|c|}
\hline Ciri & C. afer & $\begin{array}{c}\text { C. lucanusianus } \\
\text { (Maas-van de Kamer et al. 2016). }\end{array}$ \\
\hline Indumen abaksial daun & gundul & berambut tegak \\
\hline Bentuk perbungaan & membulat hingga melonjong & membulat hingga membulat telur \\
\hline Cuping daun kelopak & tegak & horizontal \\
\hline Warna bibir bunga & $\begin{array}{l}\text { putih dengan bagian tengah } \\
\text { berwarna kuning atau putih } \\
\text { dengan tepian jambon pucat- } \\
\text { jambon pekat dan warna kuning } \\
\text { di bagian tengah }\end{array}$ & $\begin{array}{l}\text { putih dengan tepian berwarna merah } \\
\text { dan bagian tengah berwarna jingga }\end{array}$ \\
\hline
\end{tabular}

\section{PERNYATAAN KONTRIBUSI PENULIS}

Konsep ide dari artikel ini disusun oleh ASDI. Pengambilan data, analisis dan interpretasi, serta penulisan artikel dilakukan oleh ASDI, MRH, dan RRI.

\section{UCAPAN TERIMA KASIH}

Ucapan terima kasih ditujukan kepada Fandri Sofieana Fastanti, S.Si, M.Si yang telah membantu menyediakan foto-foto spesimen C.afer di Herbarium Bogoriense (BO) dan Zakaria Al Anshori, S.Hut. yang telah membantu mengumpulkan sampel dari Kampus IPB Dramaga, Bogor. Terima kasih juga diucapkan untuk Arieh Mountara yang telah membantu penelusuran pustaka di Perpustakaan LSI IPB Dramaga, Bogor.

\section{DAFTAR PUSTAKA}

Anderson JW. 1912. Index of Plants. Botanic Gardens, Singapore.Singapore: Methodist Publishing House.

Andre T, Salzman S, Wendt T \& Specht CD. 2016. Speciation dynamics and biogeo-graphy of Neotropical spiral gingers (Costaceae). Molecular Phylogenetics and Evolution 103: 55-63.

Backer CA \& Bakhuizen van den Brink RC. Jr. 1968. Flora of Java. Volume III. Groningen, The Netherlands:Wolters-Noordhoff N.V. pp.74-76.

Baker G. 1898. Scitaminae. In: Thiselton-Dyer WT (ed.). Flora of Tropical Africa. Volume VII: Hydrocharideae to Liliaceae. L. The Oast House, Brook, Ashford, Kent:Reeve \& Co. Ltd. pp. 297-299.
Chen L, Foong AW, Ng A, Theo J \& Tang J. 2015. 1001 Garden Plants in Singapore. Ed. Ke-3. Singapore: National Parks.

Crouch NR, Smith GF \& Condy G. 2007. Costus afer Ker Gawl. Flowering Plants of Africa. 60: 52-57.

Djarwaningsih T. 2010. Rekaman baru beberapa jenis tumbuhan di Jawa. Floribunda 4(1): 15 $-17$.

Edeoga HO \& Okoli BE. 1996. Apomictic behaviour in Costus afer-Costus lucanusianus (Costaceae) complex in Nigeria. Feddes Repertorium 107(1-2): 75-82.

Fayaz A. 2011. Encyclopedia of Tropical Plants: Identification and cultivation of over 3,000 tropical plants. Sydney, Australia:UNSW Press.

Gledhill D. 2008. The Names of Plants. Ed. Ke-4. Cambridge, UK: Cambridge University Press.

Hariri MR \& Irsyam ASD. 2018. Catatan tentang Solanum diphyllum L. (Solanaceae) ternaturalisasi di Pulau Jawa. Al-Kauniyah 11(1): 25-32.

Heenan PB, Breitwieser I, Glenny DS, de Lange PJ \& Brownsey PJ. 1998. Checklist of dicotyledons and pteridophytes naturalised orcasual in New Zealand: additional records 1994-96. New Zealand Journal of Botany. 36: 155-162.

Hooker WJ. 1857. Curtis's Botanical Magazine. Volume 83. London: Reeve \& Co.

Irsyam ASD \& Chikmawati T. 2018. Ikhtisar Suku Rutaceae di Madura. Floribunda 5(8): 277290.

Ker Gawler JB. 1823. The Botanical Register 8: t. 683. London: James Ridgway.

Lock JM. 1984. Notes on East African Zingiberaceae. Kew Bulletin 39(4): 837-843. 
Maas PJM. 1979. Notes on Asiatic and Australian Costoideae (Zingiberaceae). Blumea 25: 543 -549 .

Maas-van de Kamer H, Maas PJM, Wieringa JJ \& Specht CD. 2016. Monograph of African Costaceae. Blumea 61: 280-318.

Randall RP. 2007. The introduced flora of Australia and its weed status. Waite Campus, University of Adelaide, Australia: CRC for Australian Weed Management.

Richardson DM, Pysek P, Rejmanek M, Barbour MG, Panetta FD \& West CJ. 2000. Naturalization and invasion of alien plants: concepts and definitions. Diversity and Distributions. 6: 93-107.

Rifai MA \& Puryadi D. 2008. Glosarium Biologi. Jakarta: Pusat Bahasa Departemen Pendidikan Nasional.

Rugayah, Retnowati A, Windadri FI \& Hidayat A.
2004. Pengumpulan Data Taksonomi. Dalam: Rugayah, Widjaja EA \& Praptiwi (eds.). Pedoman Pengumpulan Data Keanekaragaman Flora. Bogor: Puslit-LIPI.pp. 542.

Specht CD \& Stevenson DWm. 2006. A new phylogeny-based generic classification of Costaceae (Zingiberales). Taxon 55(1): 153163.

Sullivan JJ, Williams PA, Cameron EK \& Timmins SM. 2004. People and time explain the distribution of naturalized plants in New Zealand. Weed Technology 18: 1330-1333.

Suwandi TRR. 1995. Revisi Marga Costus Linnaeus (Zingiberaceae) di Malesia. Tesis Program Pascasarjana, Institut Pertanian Bogor. Bogor. 